\title{
Percepções de licenciandos sobre avaliação de aprendizagens nos anos iniciais: um olhar sobre as observações
}

\author{
Licensee's perceptions about learning evaluation: a look at observations
}

\author{
Valéria Risuenho Marques ${ }^{1}$
}

\section{Resumo}

Este artigo tem como objetivo apresentar os resultados do projeto de pesquisa intitulado "Percepções de Licenciandos sobre avaliação de aprendizagens nos anos iniciais do Ensino Fundamental" e discuti-los. 0 projeto foi desenvolvido na turma de Estágio de Docência II do curso de Licenciatura Integrada em Ciências, Matemática e Linguagens da UFPA. Quanto à avaliação formativa, ancoramo-nos em Fernandes (2008); sobre a concepção de que a avaliação precisa objetivar a melhoria das aprendizagens, assentamonos em Borralho, Lucena e Brito (2015) e no que diz respeito à proposição de práticas avaliativas formais e informais, em Mondoni e Lopes (2017). Metodologicamente, trata-se de uma pesquisa de caráter descritivo desenvolvida por etapas: estudos teóricos, observação, grupo de discussão e análise do material empírico. As análises das transcrições dos grupos evidenciam: prevalência de práticas que não consideram ensinoaprendizagem-avaliação como intrínsecas a um mesmo processo; práticas de ensino pautadas, sobretudo, no uso do livro didático; utilização da avaliação para classificar; uso da prova como instrumento avaliativo predominante nos anos iniciais; rara utilização de feedback; ausência de autoavaliação pelos alunos. Das percepções dos licenciandos, nota-se que embora os professores apresentem um discurso que sinaliza a utilização da avaliação formativa em suas práticas, as observações ainda identificam práticas avaliativas condizentes com características classificatórias, somativas.

Palavras chave: avaliação das aprendizagens; formação inicial; matemática; percepções; anos iniciais.

\begin{abstract}
This article aims to present the results of the research project entitled "Graduates' Perceptions on Learning Assessment in the Early Years of Elementary School" and discuss them. The project was developed in the Teaching Internship II class of the Integrated Degree in Science, Mathematics and Languages at UFPA. As for formative assessment, we are anchored in Fernandes (2008); on the concept that assessment needs to aim at improving learning, we are based on Borralho, Lucena and Brito (2015) and with regard to the proposition of formal and informal assessment practices, in Mondoni and Lopes (2017). Methodologically, it is a descriptive research developed in stages: theoretical studies, observation, discussion group and analysis of the empirical material. The analyzes of the groups' transcripts show: prevalence of practices that do not consider teaching-learning-assessment as intrinsic to the same process; teaching practices based mainly on the use of textbooks; use of evaluation to classify; use of evidence as a predominant assessment tool in the early years; rare use of feedback; absence of self-assessment by students. From the graduates' perceptions, it is noted that although the teachers present a speech that signals the use of formative assessment in their practices, the observations still identify evaluative practices consistent with the classification, summative characteristics.
\end{abstract}

Keywords: learning assessment; Initial formation; mathematics; perceptions; initial years.

\footnotetext{
${ }^{1}$ Universidade Federal do Pará | vrisuenho@ufpa.br
} 


\title{
Introdução
}

A iniciativa em propor a investigação sobre os caminhos da avaliação na formação inicial de professores adveio de estudos e discussões no âmbito do Projeto de cooperação internacional entre a Universidade Federal do Pará (UFPA) e a Universidade de Évora (UEPortugal) intitulado "Avaliação e Ensino na Educação Básica em Portugal e no Brasil: relações com as aprendizagens" (AERA), aprovado pelo Edital CAPES-FCT 2013. Resultados do mencionado projeto evidenciam que,

\begin{abstract}
podemos afirmar que mesmo que a expectativa de melhoria de aprendizagens esteja fortemente presente nas preocupações dos professores (nas escolas Belenenses e Éborenses), parece não haver práticas letivas deliberadas que demonstrem conhecimento e/ou consideração para com um referencial teórico argumentativo/indicativo de que as relações entre práticas de ensino e aprendizagens são imbricadas às práticas de avaliação (LUCENA, p. 5, 2017).
\end{abstract}

Outro aspecto sinalizado no âmbito do Projeto AERA é que "a avaliação de natureza formativa é quase que ausente dentro dos resultados do projeto AERA (principalmente em relação ao contexto brasileiro)" (LUCENA, p. 6, 2017). Diante destes resultados e atuando em turmas de estágio de Docência, fizemos a proposição do projeto que ora apresentamos e discutimos, pois, entendemos a necessidade de envolver também os professores em formação inicial nos estudos e nas discussões que permitam a compreensão de concepções e instrumentos de avaliação, de modo que esses sujeitos apropriem-se de fundamentos que sustentem uma prática voltada às características formativas de avaliação.

Nesse sentido, apresentamos os resultados, ainda que parciais, mas já revelando informações importante para as questões levantadas do projeto de pesquisa intitulado "Percepções de Licenciandos sobre avaliação de aprendizagens nos anos iniciais do Ensino Fundamental", aprovado pelo Edital 05/2017 PROPESP/PRODOUTOR/UFPA. O referido projeto tem como objetivo analisar a percepção dos graduandos, do curso de Licenciatura Integrada em Ciências, Matemática e Linguagens (LICML) para os Anos Iniciais do Ensino Fundamental, da Faculdade de Educação Matemática e Científica da Universidade Federal do Pará - no contexto do tema Estágio de Docência II - acerca de práticas avaliativas e instrumentos utilizados para avaliar os alunos nas aulas de matemática, nos anos iniciais do Ensino Fundamental.

Diante disto, ancoramo-nos nos estudos de Fernandes (2008) que, ao tratar da importância do papel do professor no desenvolvimento da avaliação para as aprendizagens, defende essa avaliação como atividade indissociada do processo de ensino aprendizagem, portanto, imprescindível como instrumento formativo; em Borralho, Lucena e Brito (2015) quando - em seu artigo "Avaliar para melhorar as aprendizagens" - dão ênfase à importância da avaliação estar a serviço da melhoria das aprendizagens; e em Mondoni e Lopes (2017) que discutem como a diversidade de instrumentos de avaliação, na perspectiva da avaliação formativa, pode contribuir para uma formação matemática significativa.

A pesquisa tem caráter descritivo, pois se interessou pelos significados que os próprios pesquisadores davam às coisas e possui enfoque indutivo para as análises. Para a consecução dos objetivos, o trabalho foi organizado em etapas, a saber: estudos teóricos, observação, grupo de discussão e análise do material empírico.

Os resultados preliminares apresentados neste artigo trazem a discussão de parte dos excertos das transcrições dos grupos participantes, evidenciando, dentre outros aspectos: 
prevalência de práticas que não consideram ensino-aprendizagem-avaliação como intrínsecas a um mesmo processo; práticas de ensino pautadas, sobretudo, no uso do livro didático; utilização da avaliação para classificar os alunos; uso da prova como instrumento avaliativo predominante nos anos iniciais; rara utilização de feedback; ausência de autoavaliação pelos alunos. $O$ destaque em relação às percepções dos licenciandos, nesse contexto, refere-se ao fato de que os professores apresentam um discurso que sinaliza a utilização da avaliação formativa em suas práticas, todavia, a partir das observações acerca das ações avaliativas dos docentes, ainda foram identificadas práticas condizentes com características classificatórias, somativas.

\section{Avaliação das aprendizagens}

O trabalho em turmas de Estágio de Docência impõe-se como oportunidade na proposição em integrar ensino e pesquisa aos docentes em formação inicial, no sentido de que possam articular o arcabouço teórico ao material empírico, em busca de condições que os permitam pensar criticamente e propor metodologias que cuidem das aprendizagens dos alunos. Neste sentido, compactuamos com Ghedin et al em sua reflexão sobre esse discente em formação:

Pensa-se num profissional que seja capaz de atuar competentemente como docente e produzir conhecimento sistemático a partir dessa prática. Compreende-se que o professor é competente a medida que pesquisa. Ele alia a docência à pesquisa como forma de articular a teoria-prática como forma de expressar sua competência técnica e seu compromisso político com a práxis de professor (GHEDIN et al, 2015, p. 169).

Envolver os graduandos partícipes do tema Estágio de Docência II em atividades para além das praticadas em disciplinas do estágio é dar condições desse graduando pensar e repensar sobre a prática que ele observa e, além disto, conjecturar: o que eu faria se estivesse no lugar do professor observado? Consideramos que

(...) a teoria tem importância fundamental na formação de docentes, pois dota os sujeitos de variados pontos de vista para uma ação contextualizada, oferecendo perspectivas de análise para que os professores compreendam os contextos históricos, sociais, organizacionais e de si próprios como profissionais (GHEDIN et. al, 2015, p. 173).

Neste sentido, e para compor os fundamentos que sustentaram as atividades do projeto, encontramos em Luckesi (2005) a discussão sobre o que a escola pratica: se avaliação ou verificação. Para este autor, se o professor diante dos resultados conseguidos mediante uso de um instrumento de avaliação, quaisquer que sejam esses instrumentos, apenas descreve os resultados em diário de classe, sem tecer comentários e/ou dar retorno aos alunos, de modo que pudessem conhecer suas dificuldades, atribuindo uma nota, esse docente tão somente faz uma verificação. De acordo com Luckesi (2005), a avaliação cuida da "efetiva aprendizagem". E resume,

A avaliação, diferentemente da verificação, envolve um ato que ultrapassa a obtenção da configuração do objeto, exigindo decisão do que fazer ante ou com ele. A verificação é uma ação que "congela" o objeto; a avaliação, por sua vez, direciona o objeto numa trilha dinâmica de ação (Luckesi, 2005, p. 93). 
Desta maneira, vimos na concepção de avaliação formativa alternativa proposta por Fernandes (2009), a perspectiva de integração ensino, aprendizagem e avaliação. Para este autor,

Trata-se de uma avaliação mais interativa, mais situada nos contextos vividos por professores e alunos, mais centrada na regulação e na melhoria das aprendizagens, mais participativa, mais transparente e integrada nos processos de ensino e aprendizagem. Ou seja, uma avaliação que, sendo eminentemente formativa em suas formas e em seus conteúdos, é alternativa à avaliação psicométrica, de matriz behaviorista, muito baseada na avaliação somativa e na ideia da avaliação como medida (FERNANDES, 2009, p. 56).

Neste ponto de vista, a avaliação é parte integrante do processo de ensino e de aprendizagem. Faz-se presente durante o desenvolvimento de distintas tarefas que são propostas; considera o que se pretende alcançar ao final de um período escolar; possibilita a regulação, tanto dos alunos, quanto dos professores; permite aos alunos maior participação ao terem a prerrogativa da autoavaliação, além da heteroavaliação; carece de feedback qualificado para auxiliar os alunos na regulação de seu processo de aprendizagem; é transparente, pois esses alunos passam a ter ciência do que precisam desenvolver ao final desse período.

Na concepção da avaliação formativa alternativa, professores e alunos partilham responsabilidades em termos de avaliação e regulação das aprendizagens. Essa partilha requer, dentre outros aspectos, que os professores possam:

- organizar o processo de ensino;

- propor tarefas apropriadas aos alunos;

- definir previa e claramente os propósitos e a natureza do processo de ensino e avaliação;

- diferenciar suas estratégias;

- utilizar um sistema permanente e inteligente de feedback que apoie efetivamente os alunos na regulação de suas aprendizagens;

- ajustar sistematicamente o ensino de acordo com as necessidades; e,

- criar um adequado clima de comunicação interativa entre os alunos e entre estes e os professores (FERNANDES, 2009, p. 59).

No que se refere às responsabilidades dos alunos, precisam:

- participar ativamente nos processos de aprendizagem e de avaliação;

- desenvolver as tarefas que Ihes são propostas pelos professores;

- utilizar feedback que thes é fornecido pelos professores para regularem suas aprendizagens;

- analisar seu próprio trabalho mediante seus processos metacognitivos e da autoavaliação;

- regular suas aprendizagens tendo em conta os resultados da autoavaliação e de seus recursos cognitivos e metacognitivos; 
- partilhar seu trabalho, suas dificuldades e seus sucessos com o professor e com os colegas; e,

- $\quad$ organizar seu próprio processo de aprendizagem (FERNANDES, 2009, p. 59-60).

Além disto, a avaliação se materializa numa variedade de instrumentos, por isso a necessidade de ser contínua, o que significa garantir uma relação lógica entre os diversos instrumentos utilizados no processo avaliativo, buscando sempre uma coerência pedagógica e didática entre eles, e destes com os procedimentos de ensino que o professor e a professora planejaram e fizeram uso. Assim, a continuidade dos diversos instrumentos avaliativos tem a intenção também de afastar qualquer possibilidade de fragmentação e terminalidade de sua utilização, dando a este processo uma perspectiva de integralidade, coesão e coerência (SILVA, 2018, p. 2).

No que se refere às práticas de avaliação aqui contempladas, tomamos como norte as conclusões de pesquisa realizada por Black e Wiliam (1998) sobre os benefícios de práticas de avaliação formativa. O estudo em questão evidencia três resultados, quais sejam:

a) as práticas sistemáticas de avaliação formativa melhoram significativamente as aprendizagens de todos os alunos;

b) os alunos que mais se beneficiam de tais práticas são os que revelam mais dificuldades de aprendizagem;

c) os alunos que frequentam aulas em que a avaliação predominante é de natureza formativa obtêm melhores resultados em exames e provas de avaliação externa do que os alunos que frequentam aulas em que a avaliação é essencialmente somativa.

Nos estudos de Hoffman (2005), evidencia-se um aspecto relevante, quanto ao processo de avaliação, pois a estudiosa faz referência aos tempos de aprendizagem e ressalta que cada aluno, dentro de uma mesma sala de aula, aprende em tempos e de modos diferenciados. De acordo com a autora,

Não há como delimitar tempos fixos para a aprendizagem, porque é um processo permanente, de natureza individual, experiência singular de cada um. Não há sentido em valorizar os pontos de chegada, porque são sempre pontos de chegada, provisórios. O importante é apontar os rumos do caminho, ajustar os passos ao esforço necessário, torná-lo tão "sedutor" a ponto de aguçar a curiosidade do aprendiz para o que está por vir (HOFFMAN, 2005, p. 40).

Neste sentido, é importante que se considere o passo a passo, os avanços, que se identifiquem as dificuldades para se propor intervenções que auxiliem os alunos à superação. Avaliação é intrínseca ao processo de ensino e aprendizagem. A mensuração e a certificação são necessárias, mas precisam ser vistas como apenas um componente de um processo maior. Não se pode tomar como referência de aprendizagem apenas a aplicação de um instrumento ao final de um ciclo de atividades ou ao final de um ano letivo. Faz necessário compreender a relevância de uma concepção que permita visualizar, prioritariamente, o processo, a regulação das aprendizagens, as intervenções que estimulem a superação de dificuldades, a elaboração de feedbacks que permitam a metacognição, a seleção de tarefas para auxiliar no ensino e na aprendizagem.

Assim, considera-se que, para contemplar a diversidade de ritmos e estilos de aprendizagem, cabe ampliar o leque de opções quanto aos instrumentos para proceder à avaliação (BORRALHO; LUCENA; BRITO, 2015). Mondoni (2008) em sua pesquisa de 
mestrado utilizou instrumentos de avaliação formal e informal para o desenvolvimento da avaliação de alunos do Ensino Fundamental. Os instrumentos de avaliação informal utilizados foram: o blog, o relatório, cartas, caderno piloto, autoavaliação, portfólio. De acordo com Mondoni: "com as cartas, pude perceber a riqueza de informações sobre as dificuldades dos alunos e sobre suas aprendizagens, o que possibilitou outro entendimento acerca do desempenho não satisfatório de alguns" (2008, p. 83).

No que se refere à autoavaliação,

Ressaltamos que a autoavaliação é extremamente importante como instrumento de avaliação das aprendizagens e que precisa ser praticado pelo aluno em parceria com o professor de forma continua, permitindo ao discente o "conhecer do aprender", ou seja, a reflexão sobre o que estudou e como fez isso e ao professor planejar suas intervenções (CONTENTE et all, 2016, p. 9).

Outra compreensão contemplada neste texto é que "o principal propósito da avaliação das aprendizagens terá que ser a melhoria dessas mesmas aprendizagens e se assim não for, a avaliação não cumpre o seu principal objetivo" (BORRALHO; LUCENA; BRITO, 2015, p. 34). Além disto, "a diversificação de instrumentos de avaliação é crucial para que tenhamos informação de diversa natureza e assim podermos ter uma clara e mais objetiva percepção das aprendizagens e do ensino" (BORRALHO; LUCENA; BRITO, 2015, p. 34).

\section{Metodologia}

A pesquisa possui caráter descritivo, interessa-se pelos significados que os próprios pesquisados dão as coisas e possui enfoque indutivo para as análises realizadas, portanto, é uma pesquisa classificada como qualitativa (GODOY, 1995). Desenvolveu-se em quatro etapas: estudos teóricos, observação, grupo de discussão e análise do material empírico.

Na primeira etapa, os graduandos participaram de sessões de estudos e discussão de textos. Essa fase foi de grande relevância, pois propiciou a ampliação da compreensão dos fundamentos teóricos envoltos em distintas concepções de avaliação, bem como, das relações dessas concepções com o processo de ensino e aprendizagem. Ademais, os participantes acessaram autores que evidenciavam outras possibilidades no que se refere à diversificação de instrumentos de avaliação.

Após as sessões de estudo, iniciamos a segunda etapa: a observação. Como os graduandos eram do tema Estágio de Docência II, passaram a frequentar aulas de turmas do $4^{\circ}$ ou do $5^{\circ}$ ano do Ensino fundamental. Participaram de todas as fases do processo 9 graduandos que estavam no $7^{\circ}$ semestre do curso. Neste momento, além de desenvolverem atividades peculiares ao estágio, como a observação e anotações em diário de bordo, realizaram registros tendo como referência a matriz de observação utilizada no Projeto AERA². Na etapa das observações, foram alocadas 30 horas de atividades.

A matriz em questão é composta por três objetos: práticas de ensino, práticas de avaliação e aprendizagens dos alunos. Vale ressaltar que - embora considerando que

\footnotetext{
2 Projeto de cooperação internacional entre a Universidade Federal do Pará (UFPA) e a Universidade de Évora (UE-Portugal) intitulado "Avaliação e Ensino na Educação Básica em Portugal e no Brasil: relações com as aprendizagens" (AERA), aprovado, em março de 2014, pelo Edital CAPES-FCT 2013.
} 
esses três objetos não se separam por encontram-se imbricados no processo educacional a estratificação utilizada foi pensada para favorecer a organização didático-metodológica e, como maneira de, a partir da seleção de dimensões, orientar o que precisa ser observado e analisado.

Quadro 1 - Matriz de Investigação (AERA)

\begin{tabular}{|c|c|}
\hline Objetos & Dimensões \\
\hline \multirow{8}{*}{ Práticas de Ensino } & Organização e desenvolvimento do ensino \\
\hline & Recursos, materiais e tarefas utilizados \\
\hline & $\begin{array}{c}\text { Dinâmicas de sala de aula (e.g., trabalho de grupo; trabalho em } \\
\text { pares; trabalho individual; organização das discussões) }\end{array}$ \\
\hline & Papel do professor \\
\hline & Papel dos alunos \\
\hline & Estrutura da sala \\
\hline & Percepções dos professores \\
\hline & Concepção dos alunos \\
\hline \multirow{11}{*}{ Práticas de Avaliação } & $\begin{array}{c}\text { Integração/Articulação entre os processos de } \\
\text { ensino/avaliação/aprendizagem }\end{array}$ \\
\hline & $\begin{array}{c}\text { Utilizações da avaliação (e.g., para classificar, para orientar, para } \\
\text { regular, para melhorar) }\end{array}$ \\
\hline & $\begin{array}{l}\text { Instrumentos de avaliação predominantes (e.g., testes, trabalhos } \\
\text { escritos, questões orais, listas de verificação, tarefas de sala de aula) }\end{array}$ \\
\hline & Natureza, frequência e distribuição de feedback \\
\hline & Dinâmicas de avaliação (e.g., Autoavaliação, Heteroavaliação) \\
\hline & Natureza da avaliação formativa (Formal e Informal) \\
\hline & Natureza da avaliação sumativa (Formal e Informal) \\
\hline & Papel do professor \\
\hline & Papel dos alunos \\
\hline & Percepções dos professores \\
\hline & Concepções dos alunos \\
\hline \multirow{4}{*}{$\begin{array}{l}\text { Aprendizagens dos } \\
\text { alunos }\end{array}$} & Participação dos alunos (dinâmicas, frequência e natureza) \\
\hline & $\begin{array}{l}\text { Percepções/Concepções dos professores/Alunos sobre os } \\
\text { contributos para a aprendizagem (e.g., tarefas, qualidade do } \\
\text { ensino, natureza e dinâmica das aulas, avaliação, feedback }\end{array}$ \\
\hline & Relação pedagógica com os professores \\
\hline & Percepções/Concepções dos diferentes intervenientes \\
\hline
\end{tabular}

Antes de os graduandos ingressarem nas salas de aulas para a etapa das observações, tivemos um momento de estudo da matriz. Esse momento foi relevante para que os graduandos tirassem dúvidas e solicitassem esclarecimentos sobre aspectos contemplados nesse documento.

Concluída essa etapa, passamos aos grupos de discussão. Nestes, os graduandos relatavam os aspectos observados durante a estada em turmas de $4^{\circ}$ ou $5^{\circ}$ anos do Ensino Fundamental. As reuniões de grupo de discussão foram gravadas e os relatos foram subsidiados por questionamento por parte da coordenadora do projeto ou de quaisquer participantes, de modo que houvesse entendimento do que estava sendo relatado. Finalizados todos os momentos de grupo de discussão, fez-se as transcrições dos áudios.

Para este artigo, discutimos alguns resultados da pesquisa, sobretudo, os que compõem o objeto "Práticas de Avaliação". Cabe esclarecer que a matriz de observação foi 
incluída neste texto, na íntegra. No entanto, as dimensões "percepções de professores" e "concepções dos alunos" não foram contempladas no momento da observação.

\section{Análises}

Tomando como referência a Matriz de Observação do Projeto AERA, para este texto, serão apresentados e discutidos, do objeto Práticas de Avaliação, as dimensões: integração/articulação entre os processos de ensino/aprendizagem/avaliação; utilização da avaliação; instrumentos de avaliação predominantes; natureza, frequência e distribuição de feedback; dinâmicas de avaliação; natureza da avaliação formativa; natureza da avaliação sumativa; papel do professor e papel do aluno.

No que se refere à "Integração/Articulação entre os processos de ensino/avaliação/aprendizagem", os graduandos relataram que percebiam práticas isoladas. As atividades de ensino eram, de modo geral, utilizadas a partir do livro didático e às crianças era solicitado que resolvessem as atividades e, algumas vezes, essas atividades não eram corrigidas. De acordo com alguns excertos:

Realmente, assim, eu não vi esse processo todinho acontecendo, ficou alguma coisa, um buraco, um vácuo nisso dessa integração (Graduando1).

São coisas separadas (...) Porque a gente percebia que as atividades que ela passava no quadro eram só de reforço, era só de fixação. Focado naquilo que ela achava que eles tinham dificuldade. Mas, não havia essa integração de ensino/avaliação/aprendizagem, porque não havia um retorno. Era só aquele exercício de fixação e só. Se estava errado ou certo, não havia um retorno (Graduando2).

Durante o período em que observaram as turmas, os graduandos não perceberam a integração entre ensino-aprendizagem-avaliação. Um deles fez referência ao vácuo e outro observou que o tratamento era separado. Em relação a essa dimensão, as práticas observadas vão de encontro ao que Fernandes (2009) propõe quanto à integração e à inseparabilidade entre esses processos. $\bigcirc$ Graduando2 enfatizou que as atividades utilizadas para o ensino eram "só aquele exercício de fixação e só", "não havia retorno". Neste aspecto, o graduando faz referência à ausência de feedback. As atividades encerravam-se em si mesmas, não remetiam a um repensar, a um reelaborar.

Ainda fazendo referência à integração entre ensino, aprendizagem e avaliação, e evidenciando a ausência de feedback, outro graduando relata

"... o que deu pra verificar é que ela ensinava, botava os exercícios para que os alunos fizessem, corrigia... Esse feedback que ela dava... Só que um detalhe, ela fazia a correção, vamos supor de matemática, ela fazia a correção no quadro, mas ela não tirava a dúvida que o aluno possivelmente poderia ter naquele momento que ele foi levar pra que ela verificasse. Se acertou ela dava o visto. É aquilo que nós falamos, "volta lá e tenta fazer!". Podia nortear um pouco o aluno, de que modo, até onde ele não conseguiu resolver, pra que ela pudesse abrir a porta do saber pra que ele chegasse ao final" (Graduando4).

No que tange à dimensão "utilização da avaliação", os graduandos verbalizaram: 
"... era para classificar. Tanto que muitas vezes na fala dela ela dizia "olha, se não se dedicar não vai passar de ano". O que muitos professores discursam pro aluno se dedicar mais. Não havia essa avaliação de orientação e pra regular" (Graduando2).

... exemplo: prova escrita! Prova escrita pra avaliar. Não vi uma questão de passar dever de casa pra dar, vamos dizer, pra dar ponto. Vamos dizer assim, pra incentivá-los. "Para classificar, orientar, regular, melhorar", bem, para classificar sim, né?! Pra dar uma nota... Mas para orientar, bem, não sei se caberia o caso, mas quando tinha ela chamava os pais pra pedir um maior apoio de incentivar a criança a estudar. Regular... É, talvez, também. Para melhorar, creio que não nesse enfoque que tá aqui. Que aí, creio que nesse caso aqui seria pra pelo menos ela refletir sobre a própria prática e melhorar as questões de ensino (Graduando3).

O Graduando2 destaca que a prática avaliativa do docente por ele observado era para classificar. Esse classificar associado a um alerta ou mesmo a uma ameaça de reprovação. Os aptos, ao final do ano letivo, receberão a certificação que lhes garante avançar para o ano letivo subsequente; os que não obtiverem os níveis, que permitiriam seguir para o ano subsequente, ficarão retidos, reprovados. A prática observada não dava indícios também de que era utilizada para reorientar a prática do professor ou do aluno, tampouco, como instrumento que poderia regular o processo.

O Graduando3, por sua vez, trouxe como destaque a prova. De acordo com o relato, essa prova era usada para classificar. Outro aspecto evidenciado, diz respeito à orientação, isto é, a avaliação utilizada para orientar ou reorientar o processo de aprendizagem dos alunos. Quanto a isto, o estudante comenta: "quando tinha ela chamava os pais pra pedir um maior apoio de incentivar a criança a estudar". É possível afirmar que o resultado da avaliação era usado para informar aos pais acerca do desempenho do aluno (filho) e, do mesmo modo, para pedir apoio, quanto à necessidade de maior cobrança com o filho em relação às tarefas da escola. Quanto à criança, que deveria ser a principal interessada no processo, nada foi observado sobre a orientação ou feedback.

A respeito da dimensão "instrumentos de avaliação predominantes", o graduando Graduando3 destaca como principal instrumento a prova e reproduz parte de um diálogo presenciado durante as observações:

Prova escrita! Questão oral, não. Lista de verificação... não. É, aqui, tarefa na sala de aula, como uma questão de exercícios, deveres, ela perguntava pros alunos, mas era sempre pro geral... É, as vezes ela dizia:

Profa-regente.: Fulano!

Aluno: Tia, eu quero responder!

Profa.-regente: Não. Você, responde!

Mas era mais nesse sentido de treiná-los pra prova. Ela dizia: esse assunto aqui não vai cair do mesmo jeito, mas esse assunto vai cair na prova! No caso da soma (Graduando3).

A partir das falas do diálogo reproduzido, é possível afirmar que, além da prova ser o instrumento privilegiado na sala de aula observada, o graduando evidencia que ocorria uma espécie de treinamento para que o aluno pudesse realizá-la. Além disto, os exercícios 
resolvidos em sala traziam semelhanças e/ou aspectos que seriam exigidos de maneira similar no teste. Nessa perspectiva, a pesquisa realizada por Lucena, Dias e Borralho, indica que

Parece haver uma sujeição das avaliações do contexto escolar para com as provas externas, no sentido que aquelas precisam repetir "modelos" postos por estas a fim de promover maior segurança para com os resultados dos diagnósticos (de desempenho dos estudantes) realizados pelos órgãos competentes (Ministério da Educação/Secretarias de Educação) (2018, p. 268).

Ainda no que se refere ao instrumento avaliativo predominante, vejamos o excerto a seguir:

Eu perguntei a ela que tipo de avaliação, se ela tinha somente a prova, ela me informou que a prova era um dos. Agora, ela não fazia registro individual, manuscrito, mas deu pra perceber que ela conhecia cada um dos alunos. (...) Uma coisa que ela falou também, que os pais exigiam que tivesse prova, porque para os pais se não tivesse prova eles não tavam aprendendo. Ela poderia chegar e fazer trabalho, mas não adiantava, os pais queriam ver o retorno dos filhos através de prova. Se era nota azul, nota vermelha, nota máxima, mínima... Isso aí é o parâmetro do pai, então tinha que ter isso aí (Graduando4).

O Graduando 4 indica que a professora menciona não ser a prova o único instrumento utilizado para avaliar. No entanto, esse discente não percebeu a realização de nenhum tipo de registro ou a utilização de outro instrumento. Ainda segundo o graduando, a docente conhecia todos os estudantes da classe, e isso, de acordo com as observações, parecia suficiente. Outro aspecto destacado faz referência à cobrança dos pais pela permanência da realização das provas: o resultado da prova, isto é, a nota atribuída a cada aluno servia como um parâmetro de aprendizagem ou não aos pais.

Sobre a "natureza, frequência e distribuição de feedback", os graduandos relatam:

Distribuição de feedback era mais essa questão do aluno vir e ela: tá errado! Vai fazer de novo! Não era uma questão de demonstrar outros caminhos, outras formas de seguir, ou de pelo menos fazer uma mediação: começar e deixar que ele completasse o resto, através do raciocínio próprio, vamos dizer assim (Graduando3).

o feedback que ela dava aí era mandar eles voltar e tentar resolver. Porque, o que acontecia? Ela fazia o exercício na lousa, eles tentavam resolver e faziam uma fila pra que ela desse o visto. O importante pra eles era o visto. O importante pra eles era a professora olhar o visto, eu vou mostrar pra minha mãe e dizer "olha, eu fiz! A professora rabiscou". Aí quando ela via que tava errado ela dizia "eu não te expliquei isso aí?! Vai e tenta de novo, deixa de preguiça!". O feedback que ela dava era isso (Graduando4).

De acordo com as percepções dos graduandos, o docente até dava feedback, porém, tratava-se de um feedback não qualificado, que não contribuía para que os alunos repensassem e revissem as estratégias de pensamento (as quais porventura tivessem 
utilizado) para posteriormente reelaborá-las a fim de resolver a atividade. Era apenas uma espécie de volte ao seu lugar e tente fazer novamente.

Outro aspecto levantado pelo Graduando 4 faz referência à relevância do visto para os alunos. Esse visto servia como uma comprovação que era dada aos pais para indicar que os filhos realizavam as tarefas solicitadas pela docente. Quanto ao tipo de feedback, "eu não te expliquei isso aí?! Vai e tenta de novo, deixa de preguiça!", servia mais como uma repreensão, pois não permitia aos alunos, como já mencionado, repensar, rever, reelaborar.

Na perspectiva de feedback advogado por Fernandes (2008),

Os alunos precisam de orientações sistemáticas e de avaliações do seu trabalho e do seu desempenho que os ajudem a melhorar as suas aprendizagens, que os estimulem e que os motivem a ir tão longe quanto possível, quer reconhecendo os seus progressos e sucessos, quer ajudando a ultrapassar os seus pontos fracos. Ou seja, os alunos precisam de feedback sobre os processos e produtos de seus comportamentos sociais (2008, p. 97).

Além disto,

O feedback, em si mesmo, não resolve qualquer problema se não for devidamente pensado, estruturado e adequadamente integrado no processo de aprendizagem dos alunos. Na verdade, tem de ser bem mais do que uma simples mensagem: temos de garantir que o que se pretende comunicar aos alunos seja efetivamente percebido de forma que eles possam saber o que fazer com tal comunicação (FERNADES, 2008, p 97).

No que se refere às "dinâmicas de avaliação", mais especificamente, solicitando aos graduandos observarem sobre a prática de autoavaliação e heteroavaliação, mencionaram:

A autoavaliação, eu acho que, assim, não tem não. E a heteroavaliação tem, tem sempre alguém avaliando ela. Ou o aluno, eu acho que é mais o aluno que fica... E a coordenação todinha, que entra e sai, eles procuram saber o que ela tá fazendo, todas as provas passam pela coordenação pedagógica. Se não tá de acordo com o que é, volta pra ela fazer os ajustes conforme a coordenação pedagógica. Então, ela sempre é heteroavaliada (Graduando1).

Autoavaliação não tinha, que seria ou os alunos se avaliarem ou avaliarem a professora ou ambos se avaliarem. O foco da avaliação era sempre em cima do aluno e não de ambos dentro do processo (Graduando3).

O Graduando1 faz referência a não percepção de prática de autoavaliação. E, em relação à heteroavaliação, menciona que esta prática é comum da coordenação da escola em relação à prática da professora. Todavia, o que a dimensão da matriz solicitava era sobre: se ocorria a heteroavaliação entre professor-aluno, aluno-aluno.

O Graduando3 enfatiza "O foco da avaliação era sempre em cima do aluno e não de ambos dentro do processo", em outras palavras, não havia nenhuma dinâmica que incentivasse a auto ou a heteroavaliação. No processo observado, o professor figurava como avaliador por excelência, não havia abertura nem incentivo aos alunos de se autoavaliarem.

No tocante à natureza da avaliação, os graduandos evidenciam: 
Era "avaliação somativa", que vai avaliando bimestralmente pra chegar numa classificação, era classificatório. (Graduando2)

É, aqui talvez tivesse alguma avaliação formativa, mas era mais sobre a questão de discussão. Eles se reuniam e se o rendimento da turma tivesse baixo eles discutiam entre si uma outra forma de avaliar, mas sempre com esse foco somativo (Graduando3).

O Graduanda2 destaca que, de acordo com o observado, a avaliação encaminhada pela docente era de natureza somativa, pois se preocupava com a classificação e pautavase em avaliações bimestrais, as quais se ocupavam em dar nota para representar o nível de aprendizagem que cada aluno estava.

O Graduando3 evidencia a preocupação da escola com rendimento escolar aquém do condizente com padrões estabelecidos para cada ano - período letivo. Essa preocupação motivava professores e coordenadores educacionais a fazerem proposições de outra forma de avaliar. Porém, essas outras formas permaneciam com características próprias de uma prática avaliativa somativa. Buscava-se apenas adequar o nível das crianças a padrões, a classificações e, ao final do período, à certificação de que estaria apto a progredir.

Tendo em consideração o "papel do professor", tivemos os relatos:

E o "papel do professor" na avaliação era esse de classificar o aluno, de somar aquelas avaliações pra ver se ele passava ou não (Graduando2).

o papel do professor seria o julgador da avaliação, porque somente ele teria o poder de dar aquela nota, transformar uma questão qualitativa em quantitativa, transformar aquilo em número (Graduando3).

Em conformidade com as observações, o professor figura como o responsável pela avaliação. É ele quem seleciona os instrumentos avaliativos ou o instrumento, já que é ele quem "decide" quem está apto ou não a passar de ano.

Relativamente, ao "papel do aluno", os graduandos evidenciaram:

E o "papel dos alunos" na avaliação era apenas de responder os exercícios, mas não havia nenhum processo de construção, de "ah, eu fiz esse exercício, o professor observou que a partir dele ele pode passar uma outra atividade", não observamos isso dessa professora (Graduando2).

O papel dos alunos aí era cobrir, marchar e bater continência. Tradicional, eles não eram críticos, não dava porque se não eles seriam críticos (Graduando4).

O papel dos alunos é procurar uma nota, procurar vencer aquele ensino pra poder passar de ano, pra cumprir uma meta somente. Não em procurar aprender com qualidade, fazer novas descobertas, novos padrões de pensamentos... Não, somente dentro daquela caixinha e receber a nota, não poder opinar sobre aquele processo de avaliação. Porque tem que ter dado a ele o direito de questionar, porque somente tiraram aquela nota. Tirou aquela nota e acabou, nada de dizer "por que você tirou?", quer dizer, aí já cai naquela questão de novo de feedback, quer dizer, inexistente (Graduando3). 
Os excertos remetem à compreensão de que o papel dos alunos no processo de avaliação é de total passividade. Recebem o instrumento utilizado para a avaliação com a nota a que the foi atribuída e não há um olhar para, diante dos "erros", repensar e rever quais dificuldades o aluno ainda evidencia. A nota é usada para dizer - dentro da escala de conhecimentos e habilidade que deveria alcançar no âmbito de um período de tempo, normalmente um bimestre - em que nível de conhecimento, de 0 a 10, o aluno encontra-se.

Outro graduando faz comparação ao que ocorre em um quartel. Segundo observação dele, "o papel dos alunos aí era cobrir, marchar e bater continência".

\section{Considerações finais}

Os graduandos partícipes da pesquisa envolveram-se em todas as etapas previstas na metodologia. Os estudos foram relevantes para favorecer o conhecimento e compreensão de diferentes concepções de avaliação e de possibilidades em termos de instrumentos utilizados para avaliar. Outro aspecto evidente foi o entendimento de que a avaliação não pode se limitar às semanas de provas, mas precisam integrar-se às práticas de ensino e aprendizagem.

No tocante às percepções dos graduandos sobre as práticas de avaliação dos professores observados, destacaram a ausência de integração entre ensino/aprendizagem/avaliação. As práticas de ensino eram pautadas em listas de exercícios e/ou em atividades do livro didático. Os docentes têm por costume utilizar os resultados das avaliações apenas para classificar, medir o nível das aprendizagens. Dos resultados dessas avaliações, nada era feito no sentido de regular a prática desse docente ou regular as aprendizagens dos alunos. A avaliação praticada não tinha como intenção cuidar da melhoria das aprendizagens. Os feedbacks, quando observados, não eram qualificados, não auxiliando, portanto, os alunos a reverem e repensarem estratégias propostas para resolução de atividades.

O instrumento avaliativo predominante nas práticas observadas era a prova e o resultado dessa prova, em uma das turmas observadas, era entregue aos pais e não era feito nenhum comentário sobre as questões que tinham maior índice de erros. Não havia nenhuma iniciativa no sentido de pôr em prática a autoavaliação e a heteroavaliação. 0 professor, nas turmas observadas, assumia a postura do avaliador, porque o papel dele, nesse sentido, era o de dizer quem estava apto ou não a prosseguir para o ano subsequente. Aos alunos, cabia escutar, copiar, fazer as tarefas e ficar à espera das orientações. No entanto, essas orientações, quando observadas, não permitiam aos estudantes reverem seus percursos, repensando-os. Limitavam-se a frases como: "eu não te expliquei isso á??! Vai e tenta de novo, deixa de preguiça!".

Diante do que fora percebido pelos graduandos, entendemos que aos professores falta o envolvimento em estudos e discussões que propiciem o conhecimento e a apropriação de aspectos teóricos relacionados às diferentes concepções de avaliação e variedade de instrumento que possam ser usados para avaliar.

Esses resultados, mesmo que parciais, já indicam que, na percepção dos Licenciandos, os Professores em exercício precisam retomar estudos e discussões que propiciem o conhecimento e a apropriação de aspectos teóricos concernentes às diferentes concepções de avaliação e variedade de instrumentos que possam ser usados para avaliar. Entretanto, o 
destaque está na proposta de uma experiência de reflexão sobre a prática ainda na formação inicial.

Incentivar os graduandos a calibrar seus olhares e registrar seus sentidos e percepções sobre a avaliação realizada na prática dos professores foi de uma importância ímpar no sentido de pensar, em sua formação inicial, sobre a importância da avaliação. Provavelmente, a experiência os auxiliará a fundamentar melhor suas escolhas quando em situação de docência a fim de romperem as justificativas com o uso de discursos esvaziados que não dão conta de promover mudanças, em termos de práticas avaliativas, que as escolas necessitam.

\section{Referências}

BLACK, P.; WILLIAM, D. Assessment and classroom learning: Assessment in Education: Principles, Policy \& Practice. mar 1998, vol. 5, Issue 1.

BORRALHO, A, LUCENA, I. C. R. Avaliação e Ensino na Educação Básica em Portugal e no Brasil: relações com as aprendizagens (AERA). In: VI Seminário Internacional de Pesquisa em Educação Matemática, 2015, Pirenópolis-GO: Anais do VI Seminário Internacional de Pesquisa em Educação Matemática, Pirenópolis-GO, 2015.

BORRALHO, A. M. Á.; LUCENA, I. C. R.; BRITO, M. A. R. de B. Avaliar para melhorar as aprendizagens em matemática. Coleção IV - Educação Matemática na Amazônia - V. 7. Belém: SBEM-PA, 2015.

CONTENTE, Márcia Pantoja et all. A autoavaliação discente como instrumento de regulação no processo de avaliação das aprendizagens. In: VII Congresso Internacional de Pesquisa (Auto)Biográfica, 2016, Cuiabá-MT: Anais VII CIPA Cuiabá-MT, 2016.

FERNANDES, Domingos. Avaliar para aprender: fundamentos, práticas e políticas. São Paulo: editora UNESP, 2008.

GHEDIN, Evandro et al. Estágio com pesquisa. São Paulo: Cortez. 2015.

GODOY, A. S. Introdução à pesquisa qualitativa e suas possibilidades. Revista de Administração de Empresas, 35(2), 57-63, 1995.

HOFFMANN, Jussara. Avaliar para promover: as setas do caminho. 7. ed. Porto Alegre: Mediação, 2005.

LUCENA, Isabel Cristina Rodrigues de. Matemática, Ciências e Língua Portuguesa: formação docente a partir da compreensão do ensino-avaliação para a melhoria das aprendizagens (no prelo). Projeto Submetido à Chamada CNPq N. 22/2016. Pesquisa e Inovação em Ciências Humanas, Sociais e Sociais Aplicadas, 2017.

LUCENA, Isabel Cristina Rodrigues de; DIAS, Josete Leal; BORRALHO, António Manuel Águas. Práticas letivasde sala de aula de matemática nos anos iniciais. Est. Aval. Educ., São Paulo, v. 29, n. 70, p. 254-274, jan./abr. 2018.

LUCKESI, Cipriano Carlos. Avaliação da aprendizagem escolar: estudos e proposições. 16. ed. São Paulo: Cortez, 2005. 
MONDONI, Maria Helena de Assis. O Processo da Avaliação no Ensino e na Aprendizagem de Matemática. Dissertação (Programa de Pós-Graduação em Ensino de Ciências e Matemática) - Universidade Cruzeiro do Sul, São Paulo/SP, 2008.

MONDONI, Maria Helena de Assis; LOPES, Celi Espasandin. O Processo da Avaliação no Ensino e na Aprendizagem de Matemática. Disponível em:

http://www2.rc.unesp.br/eventos/matematica/ebrapem2008/upload/319-1-Agt_mondoni_tc.pdf. Acesso em: 20/03/2017.

SANTOS, Sandra Augusta. Explorações da linguagem escrita nas aulas de Matemática. In: LOPES, Celi Aparecida Espasandin e NACARATO, Adair Mendes. Escritas leituras na educação matemática. Belo Horizonte: Autêntica, 2009.

SILVA, Janssen Felipe da. Avaliação do ensino e da aprendizagem numa perspectiva formativa reguladora. Disponível em:

http://smeduquedecaxias.rj.gov.br/nead/Biblioteca/Formação\%20Continuada/Avaliação/jans sen1.pdf Acesso em: 03/01/2018. 